Original Research Article

\title{
Effect of trimethoprim-sulfamethoxazole vs. norfloxacin on fecal $E$. coli resistance pattern and efficacy in patients receiving prophylaxis for spontaneous bacterial peritonitis
}

\author{
Siddhartha Dutta ${ }^{1 *}$, Shalini Chawla ${ }^{1}$, Siddharth Srivastava ${ }^{2}$, Poonam Loomba $^{3}$, Vandana Roy ${ }^{1}$
}

${ }^{1}$ Department of Pharmacology, Maulana Azad Medical College, New Delhi 110002, India

${ }^{2}$ Department of

Gastroenterology,

${ }^{3}$ Department of Microbiology,

Govind Ballabh Pant Institute of Postgraduate Medical Education and Research, New Delhi, India

Received: 11 September 2018 Accepted: 05 October 2018

\section{*Correspondence to: \\ Dr. Siddhartha Dutta, \\ Email: siddhartha.dutta87@ gmail.com}

Copyright: (C) the author(s), publisher and licensee Medip Academy. This is an openaccess article distributed under the terms of the Creative Commons Attribution NonCommercial License, which permits unrestricted noncommercial use, distribution, and reproduction in any medium, provided the original work is properly cited.

\begin{abstract}
Background: Spontaneous Bacterial Peritonitis (SBP) is an infection of ascitic fluid. It is highly mortal and recurrent condition, so prophylaxis with Norfloxacin (NOR) or Trimethoprim-sulfamethoxazole (TMP-SMX) seems to play an important role in the prevention of further episodes of SBP. Aims of the study were to assess the effect of TMP-SMX/NOR on the sensitivity pattern of fecal $E$. coli after long term prophylaxis in Spontaneous Bacterial Peritonitis (SBP) and to compare the efficacy of TMP-SMX and NOR in prophylaxis of SBP.

Methods: An interventional, prospective, open label, single center study conducted in Maulana Azad medical college, New Delhi, India. 52 patients of SBP or with high risk of SBP were screened and finally 39 patients were recruited. Stool sensitivity testing of fecal $E$. coli was done and they were divided into TMP-SMX group $(n=18)$ and NOR group $(n=21)$ according to sensitivity. After $45 \pm 3$ days (7 weeks) their stool sample was re-examined for change sensitivity pattern of $E$. coli. Efficacy variables like any episode of SBP, fever (FEV) resolution of ascites (ASC), bacteremia (BACT), extraperitoneal infection (EPI), liver transplantation (LT) or death (D) were noted throughout the period of 24 weeks.

Results: Resistance developed in $60 \%$ vs. $48 \%$ in TMP-SMX vs. NOR $\operatorname{group}(\mathrm{p}=0.46)$ after 45 days of prophylaxis. By the end of 24 weeks, Incidence of SBP (29\%vs. 25\%, p>0.99), episodes of $\mathrm{FEV}(\mathrm{P}=0.60), \mathrm{EPI}(\mathrm{p}>0.99)$, $\operatorname{ASC}(p>0.99)$ and death (14\% vs. $16 \%, p>0.99)$ were almost similar in both the groups (TMP-SMX vs. NOR) respectively.

Conclusions: Both TMP-SMX and NOR showed same degree of resistance and found equi-efficacious when administered as long-term prophylactic therapy in SBP. TMP-SMX can be a suitable as well as cost effective alternative to NOR for the prophylaxis of SBP.
\end{abstract}

Keywords: Bacterial resistance, E. coli, Liver cirrhosis, Norfloxacin, Spontaneous bacterial peritonitis, Trimethoprim-sulfamethoxazole

\section{INTRODUCTION}

Spontaneous Bacterial Peritonitis (SBP) is an infection of ascitic fluid without an evident detectable intra-abdominal surgically treatable source of infection. ${ }^{1}$ It is very common and severe complication in patients with cirrhosis and ascites. It often develops insidiously and becomes evident with the deteriorating condition of the patient. The prevalence of SBP at hospital admission ranges from $10 \%$ to $27 \% .^{2}$ The inpatient mortality rates are quite high and ranges from $20 \%$ to $40 \% .^{3}$ After first hospitalization, oneyear and two-year mortality rates for those with SBP are 
approximately $70 \%$ and $80 \%$ respectively. Recurrence rate is very common ranging from $40-70 \%$ within first year. ${ }^{4}$ The patients of cirrhosis with ascites with a coexisting gastrointestinal bleed, a previous episode of SBP or low ascitic albumin levels are at significant higher risk of developing SBP. ${ }^{4-6}$ Mostly the episodes of SBP are caused by enteric bacteria from the gut and in them, roughly $70 \%$ of the infections are due to Gram negative bacteria (GNB) and they are mostly monomicrobial in contrast to secondary peritonitis. The most common microbes found in the ascitic fluid are aerobic GNB from the family of Enterobacteriaceae. ${ }^{7,8}$ The three most common isolates are Escherichia coli (E. coli), Klebsiella pneumoniae and the Pneumococci. E. coli is the most frequently isolated GNB. ${ }^{9}$ The studies have proposed that these enteric microbes cross the intestinal mucosal barrier and seep into the mesenteric lymph nodes and further enters the systemic bloodstream through the drainage from thoracic duct. This is called as bacterial translocation. ${ }^{10}$ Since the prevalence and mortality is high and recurrence is frequent, so prophylaxis seems to play an important role in the prevention of further episodes of SBP. Review of literature reveals that at present most commonly used antimicrobial for prophylaxis is norfloxacin (NOR) which decreases the probability of recurrence of SBP from $68 \%$ to $20 \%$ and probability of GNB from $60 \%$ to $3 \% .^{11,12}$ The biggest concern at present with continuous prophylaxis is the shift in the range of pathogenic agents causing SBP and the emerging bacterial resistance due to it. ${ }^{8,13}$ Scientific literature and International guidelines like International ascites club recommendations, European Association for the study of the Liver and American Association for the Study of Liver Diseases practice guidelines reveals Trimethoprim sulfamethoxazole (TMP-SMX) is an alternative drug to norfloxacin (NOR) ${ }^{14,15}$ But very few studies were done comparing TMP-SMX to NOR in this context. Lack of use of Trimethoprim-sulfamethoxazole has been seen in past few years. But data are not clear regarding the resistance in patients with use of TMP-SMX as prophylaxis in adults with SBP or risk of SBP taking long term prophylaxis. With the revival of interest of this age-old antimicrobial, rapid emergence of fluoroquinolones resistant bacteria caused by long term prophylaxis by Norfloxacin, TMP-SMX be yet another cost-effective alternative. So, we planned this study determine the effect of both drugs on faecal flora, resistance pattern and compare their efficacy in prophylaxis of SBP.

\section{METHODS}

This was interventional, prospective, open label, single center study. The study was conducted at Department of Pharmacology, Maulana Azad medical college, Department of Gastroenterology and Department of Microbiology, Govind Ballabh Pant Institute of Postgraduate Medical Education and Research, New Delhi.

A sample size of convenience of 32 patients was taken.
The study was carried out after receiving approval from Departmental Scientific Committee and the Institutional Ethics Committee.

Proper written informed consent was taken before inclusion into the study.

\section{Inclusion criteria}

- A patient of age above 18 and below 75 years of either sex was included

- A diagnosed case of SBP or a patient with total protein in ascitic fluid less than $1.5 \mathrm{gm} / \mathrm{dl}$

\section{Exclusion criteria}

A patient with,

- Allergy to sulfonamides or fluoroquinolones

- Antimicrobial therapy in the previous two weeks prior to inclusion

- Any episode of gastrointestinal bleed

- History of any neoplasms

Consecutive patients those that were already diagnosed with cirrhosis and ascites (on the basis of clinical findings, biochemical, radiological criteria) by the clinicians were selected. All the patients included were treated as per the standard of care in the hospital and then post treatment prophylaxis was started. On day 0 or the day of hospitalization, the patients underwent the required basic and specific investigations and were given the standard of care as per the hospital protocol. The patients who met the inclusion-exclusion criteria were enrolled on day 1 of hospitalization. the patient was asked to give the first stool sample in a wide mouth container which was immediately transported to the Microbiology laboratory for microbiological examination of the fecal flora by culture and to determine the resistance pattern of E. coli in stool.

Microbiological culture recorded various species isolates viz. E. coli, Klebsiella sp., Enterococcus sp., Citrobacter etc. The samples showing $E$. coli were processed and taken to Vitec 2 system for sensitivity to TrimethoprimSulfamethoxazole and Norfloxacin. The patients were then allocated into two groups according to the sensitivity reports.

- $\quad$ Group A-Those are sensitive to TMP-SMX received TMP-SMX 160/800mg OD daily.

- Group B- Those are sensitive to NOR received NOR 400mg OD daily.

Then the patients were started on SBP prophylaxis as per their sensitivity reports for a long-term prophylaxis and were followed up for a total duration of 24 weeks from the start of prophylaxis. Along with the antimicrobial the other medications which were regularly given as a part of standard treatment protocol were multivitamins, lactulose and diuretics. 
They were instructed to get back after $45 \pm 3$ days ( 7 weeks) of starting the prophylactic treatment and give the second stool sample for microbiological examination. Similarly, the second stool sample was processed, and antimicrobial susceptibility testing was done.

This was taken as primary end point. The sensitivity pattern of $E$. coli to either drugs in respective two groups were compared. If the patient was still sensitive to the previous treatment, he/she was instructed to continue the same for long term prophylaxis. If it was found resistant to the previous treatment, then he/she was advised to take the other drug (TMP-SMX/NOR) if was found sensitive at that point of time. If found resistant to both treatments, then were given Rifaximin as a rescue medication. The patients were followed up for 24 weeks either telephonically or in person every week from the start of prophylaxis for any episode of SBP, resolution/worsening of ascites, bacteremia, extraperitoneal infection, liver transplantation or death and on the basis of these parameters the efficacy of Trimethoprim-sulfamethoxazole and Norfloxacin were compared. This was taken as secondary end point.

Extraperitoneal infections were defined as any infection which can be diagnosed clinically or aided with microbiological and biochemical investigations or imaging techniques if required and requires antimicrobial treatment for the cure.

\section{Statistical analysis}

The data was entered in MS Excel and was analyzed using statistical software Graphpad prism 7. The demographic data was presented as Mean \pm Standard deviation. The groups were compared using student's unpaired t-test. Chi square test, Fischer exact test and Mann Whitney U Test were used to compare the data with non-normal distribution. For statistical analysis a $p$ value of $<0.05$ was considered significant at a confidence interval of $95 \%$.

\section{RESULTS}

A total of 54 patients were enrolled. Of these 54, the diagnosis of SBP was ascertained in 32 and 20 had low ascitic fluid protein level. Two patients refused to consent hence excluded. Thus, a total of 52 patients were recruited. Details in the flowchart diagram (Figure 1).

\section{Antimicrobial sensitivity profile of $E$. coli at baseline}

Microbial examination on day one revealed 13 patients among 52 were found to be resistant to both TMP-SMX and NOR and hence were excluded from the study.

A total of 39 patients who were sensitive to either TMPSMX or NOR or both were continued in the study (Table 1).

Table 1: Distribution of patients according to their antimicrobial sensitivity profile of $E$. coli.

\begin{tabular}{|c|c|c|c|c|}
\hline \multirow[b]{2}{*}{ Groups } & \multirow{2}{*}{$\begin{array}{l}\text { Total } \\
\text { patients } \\
(\mathbf{n}=\mathbf{3 9})\end{array}$} & \multicolumn{3}{|c|}{ Antimicrobial sensitivity profile of $E$. coli } \\
\hline & & Sensitive to both & $\begin{array}{l}\text { Sensitive exclusively to } \\
\text { TMP-SMX }\end{array}$ & $\begin{array}{l}\text { Sensitive exclusively to } \\
\text { NOR }\end{array}$ \\
\hline Group A: TMP-SMX, n & 18 & 11 & 7 & 0 \\
\hline Group B: NOR, n & 21 & 2 & 0 & 19 \\
\hline
\end{tabular}

$\mathrm{N}=$ total number of patients finally enrolled. $\mathrm{n}=$ patients in each group

TMP-SMX= Trimethoprim-Sulfamethoxazole, NOR= Norfloxacin

Table 2: The comparison of the baseline demographic and blood parameters.

\begin{tabular}{|c|c|c|c|}
\hline & TMP-SMX (n=15) & NOR (n =19) & p value \\
\hline AGE, years ${ }^{\dagger}$ & $47.8 \pm 12.24$ & $49.263 \pm 10.61$ & $\mathrm{p}=0.71$ \\
\hline Sex, M/F & $15 / 0$ & $16 / 3$ & $\mathrm{p}=0.23$ \\
\hline Serum bilirubin $(\mathrm{mg} / \mathrm{dl})^{\dagger}$ & $9.45 \pm 6.32$ & $13.65 \pm 6.79$ & $\mathrm{p}=0.07$ \\
\hline $\operatorname{SGOT}(\mathrm{U} / \mathrm{L})^{\dagger}$ & $69.3 \pm 21.6$ & $89.47 \pm 17.99$ & $\mathrm{p}=0.007$ \\
\hline $\operatorname{SGPT}(\mathrm{U} / \mathrm{L})^{\dagger}$ & $53.3 \pm 21.6$ & $55.74 \pm 17.19$ & $\mathrm{p}=0.64$ \\
\hline $\operatorname{ALP}(\mathrm{U} / \mathrm{L})^{\dagger}$ & $195 \pm 133$ & $227.26 \pm 148.39$ & $\mathrm{p}=0.32$ \\
\hline Total protein $(\mathrm{g} / \mathrm{dL})^{\dagger}$ & $5.17 \pm 0.64$ & $5.23 \pm 0.98$ & $\mathrm{p}=0.77$ \\
\hline Serum albumin $(\mathrm{g} / \mathrm{dL})^{\dagger}$ & $1.99 \pm 0.60$ & $1.84 \pm 0.56$ & $\mathrm{p}=0.71$ \\
\hline $\mathrm{PT}(\mathrm{sec})^{\dagger}$ & $22.83 \pm 5.903$ & $24.50 \pm 6.92$ & $\mathrm{p}=0.45$ \\
\hline $\mathrm{INR}^{\dagger}$ & $2 \pm 0.5$ & $2.22 \pm 0.64$ & $\mathrm{p}=0.38$ \\
\hline Serum urea $(\mathrm{mg} / \mathrm{dL}) \dagger$ & $73.07 \pm 32.3$ & $77.96 \pm 33.17$ & $\mathrm{p}=0.66$ \\
\hline Serum creatnine $(\mathrm{mg} / \mathrm{dL})^{\dagger}$ & $1.57 \pm 0.65$ & $1.28 \pm 0.36$ & $\mathrm{p}=0.14$ \\
\hline
\end{tabular}

$\dagger=$ Mean \pm Standard Deviation, TMP-SMX= Trimethoprim-Sulfamethoxazole, NOR= Norfloxacin

$\mathrm{M}=$ male, $\mathrm{F}=$ female, $\mathrm{n}=$ number of patients, SGOT=Serum Glutamic-Oxaloacetic Transaminase, SGPT=Serum Glutamic Pyruvic Transaminase, ALP= Alkaline Phosphatase, $\mathrm{PT}=$ Prothrombin time, INR= International Normalized Ratio 
Out of 39 patients 18 were allotted to group A, i.e. TMPSMX which included 11 patients who were sensitive to both TMP-SMX and NOR and seven patients exclusively sensitive to TMP-SMX.

According to antimicrobial susceptibility reports sensitivity of E. coli came as follows:

- 13 patients were sensitive to both TMP-SMX and NOR

- 7 patients were only sensitive to TMP-SMX

- 19 patients were only sensitive to NOR

Remaining 21 of 39 patients were allotted to group B, i.e. NOR which included two patients who were sensitive to both TMP-SMX and NOR and 19 patients exclusively sensitive to NOR (Figure 1).

Both groups A and B were followed up telephonically after starting prophylaxis. During this first phase of follow up of $45\left(45^{\text {th }} \pm 3\right)$ days, a total of 34 patients turned up for stool microbiological examination. Out of which 15 were from group A and 19 were from group B.

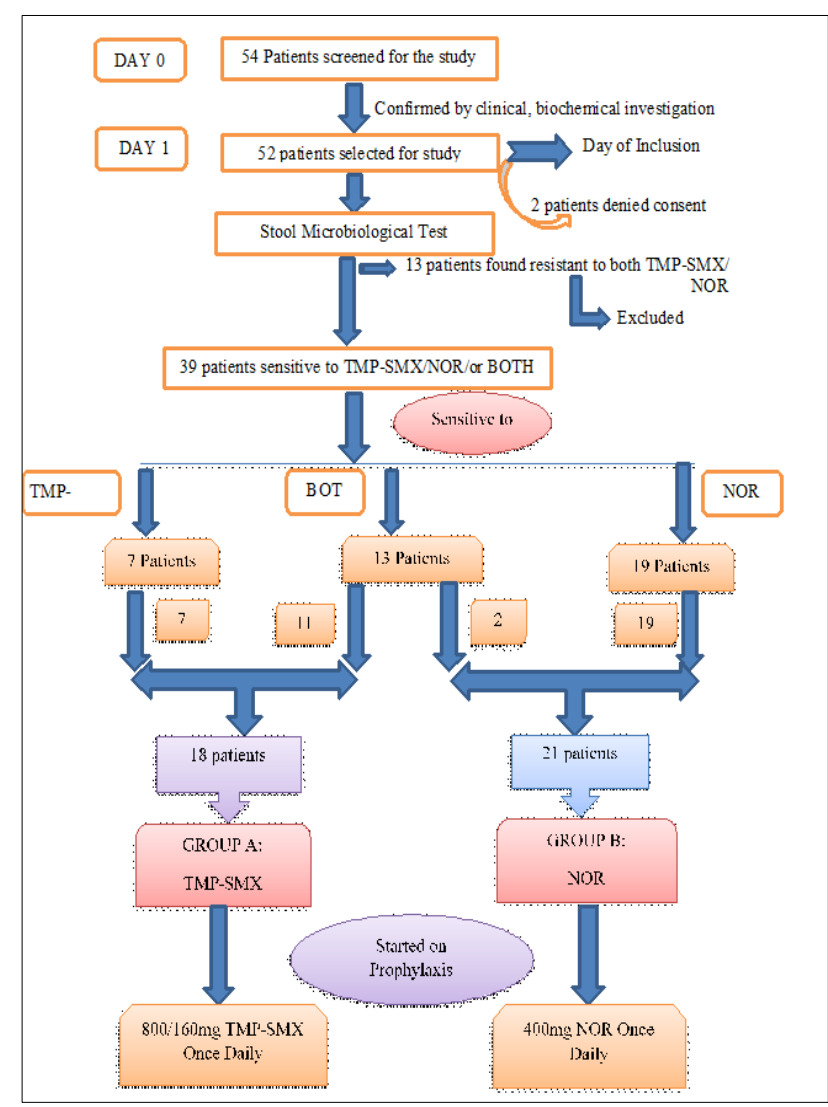

Figure 1: Overview of the study design.

Five patients were lost during the follow up, three from group A and two from group B. Summarized in Figure 2.

Finally, 34 patients were studied from group A and B which comprised of 31 males and 3 females. The baseline characteristics were almost comparable. All the data were expressed in Mean \pm SD and were well matched. The demographic data and baseline blood investigations are summarized in Table 2.

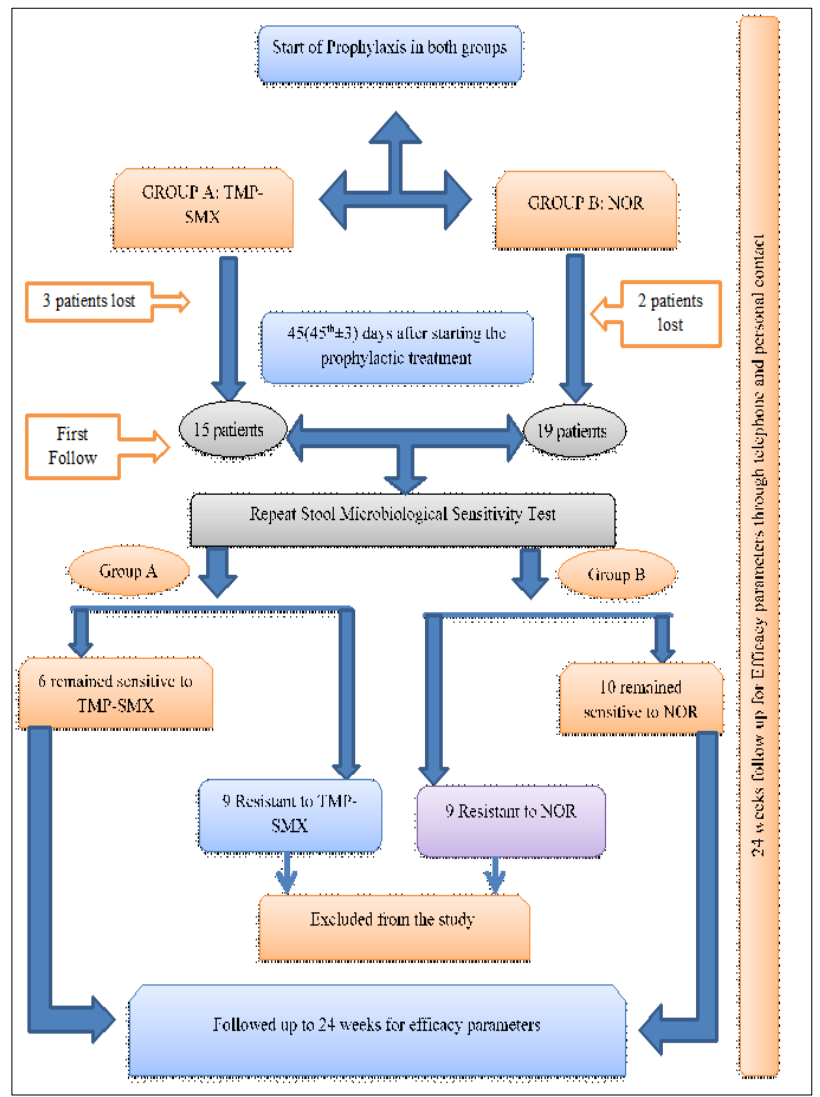

Figure 2: Overview of the study design and follow up.

\section{Antimicrobial resistance pattern of $E$. coli at $45^{\text {th }}$ day}

On the $45^{\text {th }}$ day visit of the group A(TMP-SMX) only six remained sensitive and nine patients came out to be resistant to TMP-SMX.

Table 3: The sensitivity profile of the patients at $45^{\text {th }}$ day.

\begin{tabular}{|c|c|c|c|}
\hline \multirow[t]{2}{*}{ Groups } & \multirow{2}{*}{$\begin{array}{l}\text { Total } \\
\text { patients at } \\
\text { the } \\
\text { beginning of } \\
\text { prophylaxis }\end{array}$} & \multicolumn{2}{|c|}{$\begin{array}{l}\text { Sensitivity profile } E \text {. } \\
\text { coli at } 45^{\text {th }} \text { day of } \\
\text { prophylaxis }\end{array}$} \\
\hline & & Sensitive & Resistant \\
\hline $\begin{array}{l}\text { Group A: } \\
\text { TMP-SMX, } \\
\mathrm{n}(\%)\end{array}$ & 15 & $6(40 \%)$ & $9(60 \%)^{\mathrm{NS}}$ \\
\hline $\begin{array}{l}\text { group B: } \\
\text { NOR n(\%) }\end{array}$ & 19 & $10(52 \%)$ & $9(48 \%)^{\mathrm{NS}}$ \\
\hline
\end{tabular}

$\mathrm{n}=$ number of patients in each group. $\%=$ percentage of patient in that group

TMP-SMX $=$ Trimethoprim-Sulfamethoxazole, NOR= Norfloxacin

$\mathrm{p}$ value $=0.46, \mathrm{NS}=$ not significant 
Likewise, in group B(NOR) only ten remained sensitive and nine patients found resistant to NOR.

The data on $45^{\text {th }}$ day was compared to the baseline which is described in Table 3.

It is inferred that that both the antimicrobial under this study has almost same propensity to cause bacterial resistance $(\mathrm{p}=0.46)$ (Table 3$)$.

\section{Assessment of efficacy parameters}

For assessment of the efficacy parameters only those patients were chosen from both groups who received the same medication for prophylaxis for full period of follow up of 24 weeks.

Total seven patients in TMP-SMX group and 12 patients in NOR group had developed efficacy parameters during their follow up of 24 weeks $(7+17$ weeks).

\section{Efficacy parameters}

- $\quad$ SBP- Two patients in TMP-SMX group and three patients in NOR group developed SBP during the follow up period.

- Extraperitoneal Infections (EPI)- Five Patients in TMP-SMX group and ten patients in NOR group. In this study most common extraperitoneal infections encountered were urinary tract infection (UTI), respiratory infections (RTI), sepsis and skin infections (Table 4).

- $\quad$ Fever (FEV)- Five patients in TMP-SMX group and nine patients in NOR group.

- Worsening or resolution of ascites (ASC)- Three patients in TMP-SMX group and four patients in NOR group.

- $\quad$ Liver transplantation (LT)- There was no case of any liver transplantation in both the groups.

- $\quad$ Death(D)- There was one death in TMP-SMX group and two deaths in NOR group.

Table 4: Various extraperitoneal infections between two groups.

\begin{tabular}{|llll|}
\hline $\begin{array}{l}\text { Incidence of extraperitoneal infections (EPI) in } \\
\text { both groups }\end{array}$ & $\begin{array}{l}\text { TMP-SMX } \\
\text { group }\end{array}$ & $\begin{array}{l}\text { NOR } \\
\text { group }\end{array}$ & p value \\
\hline $\begin{array}{l}\text { Episodes of } \\
\text { EPI }\end{array}$ & 7 & 10 & $\mathrm{p}>0.99$ \\
\hline Total EPI & $4(57 \%)$ & $6(60 \%)$ & $\mathrm{p}>0.99$ \\
\hline UTI, n (\%) & $1(14 \%)$ & $1(10 \%)$ & $\mathrm{p}>0.99$ \\
\hline RES, n (\%) & $2(28 \%)$ & $2(20 \%)$ & $\mathrm{P}=0.60$ \\
\hline Sepsis, n (\%) & 0 & $1(10 \%)$ & $\mathrm{p}>0.99$ \\
\hline Skin INF, n (\%) & 0 & & \\
\hline
\end{tabular}

$\mathrm{n}=$ total number of episodes of EPI. \%= percentage of a particular EPI out of total EPI. EPI=Extraperitoneal Infection, UTI= Urinary Tract Infection, RES $=$ Respiratory infection, SKIN $\mathrm{INF}=$ Skin Infection
The two groups were compared, and there was no significant difference $(\mathrm{p}>0.05)$ in any of the efficacy parameters between the two groups. The efficacy parameters are compared in Table 5.

\section{Table 5: The comparison of efficacy parameters} between the two groups.

\begin{tabular}{|c|c|c|c|}
\hline \multicolumn{4}{|c|}{ Comparison of efficacy parameters } \\
\hline & $\begin{array}{l}\text { TMP-SMX } \\
\text { group }\end{array}$ & $\begin{array}{l}\text { NOR } \\
\text { group }\end{array}$ & $p$ value \\
\hline SBP, $n$ & 2 & 3 & $p>0.99$ \\
\hline $\mathrm{BACT} / \mathrm{FEV}, \mathrm{n}$ & 5 & 9 & $\mathrm{P}=0.60$ \\
\hline EPI, $\mathrm{n}$ & 5 & 10 & $\mathrm{p}>0.99$ \\
\hline ASC, $n$ & 3 & 4 & $\mathrm{p}>0.99$ \\
\hline $\mathrm{LT}, \mathrm{n}$ & 0 & 0 & \\
\hline $\mathrm{D}, \mathrm{n}$ & 1 & 2 & $\mathrm{p}>0.99$ \\
\hline
\end{tabular}

$\mathrm{n}=$ Number of patients who had developed the efficacy parameter.

TMP-SMX $=$ Trimethoprim-Sulfamethoxazole, $\quad$ NOR= Norfloxacin

$\mathrm{SBP}=$ Spontaneous Bacterial Peritonitis, $\mathrm{BACT}=$ Bacteremia, $\mathrm{FEV}=$ Fever, $\mathrm{EPI}=$ Extraperitoneal Infections, $\mathrm{ASC}=$ Worsening or resolution of ascitic fluid, LT= liver Transplantation, D= Death

This above comparison of efficacy parameters infers that both TMP-SMX and NOR are equally efficacious in the prophylaxis of SBP.

\section{DISCUSSION}

In the present study TMP-SMX was compared to standard prophylactic therapy (NOR) and the results suggests both the drugs are comparable for the prophylaxis of SBP. There are limited studies to date comparing these two drugs and their resistance pattern in patients of SBP.

After 7 weeks $\left(45^{\text {th }} \pm 3\right.$ day $), 48 \%$ participants developed resistance to NOR. This was similar to a study by Dupeyron et al, which reported a resistance of $51 \%$ with a median of 25 days NOR prophylaxis. ${ }^{13}$ A similar study conducted by Aparicio et al, reported $42.8 \%$ resistance in a mean period of $18.5 \pm 9.8$ days. ${ }^{16}$ Another study which involved participants with hepatocellular cancer reported an overall resistance rate of $40 \% .{ }^{17}$ However, a study conducted by Novella et al, showed a resistance of $90 \%$ with a longer follow up period $\left(43 \pm 3\right.$ weeks). ${ }^{18}$

Hence, the resistance pattern to NOR observed in the present study was concordant to those previously reported.

In the present study, as many as $60 \%$ participants in TMPSMX arm developed resistance to it at the first follow up. The authors of the study could not find any literature comparing the sensitivity pattern of $E$. coli in patients of SBP taking TMP-SMX as prophylactic therapy. This could be because TMP-SMX is not commonly prescribed for prophylaxis of SBP. 
Previous studies have compared NOR with TMP-SMX in prophylaxis of SBP in terms of efficacy and tolerability of both drugs but lack the comparison in resistance pattern. ${ }^{19-21}$

A study conducted by Veen et al, in pediatric population observed $91 \%$ patients on TMP-SMX developed resistance within 6 weeks. ${ }^{22}$ Huovinen et al, reported $17.1 \%$ resistance after a month of treatment. ${ }^{23}$ Mavromanolakis E et al, studied fecal flora in patients of UTI taking TMP-SMX reported $14 \%$ resistance in 4 weeks. $^{24}$

Above studies helped to draw an idea though they were not conducted in patients of SBP.

This study, there was a resistance of $60 \%$ vs $48 \%$ in TMPSMX vs NOR arms, respectively $(p=0.46)$. It can be assumed that both drugs have similar resistance profile when given as a prophylactic treatment.

In the present study on comparison of the efficacy parameters, the incidence of SBP was almost similar in the two study groups: $29 \%$ vs. $25 \%$ (TMP-SMX vs. NOR) group $(\mathrm{p}>0.99)$.

A study conducted by Lontos $\mathrm{S}$ et al, showed $28 \%$ vs. $21.6 \%$ (TMP-SMX vs. NOR) group developed SBP. ${ }^{19}$ Lontos et al, observed the rate of SBP was same (5\% vs. $5 \%$ ) in (TMP-SMX vs. NOR) group. ${ }^{21}$ However, the results of conducted by Alvarez et al, differed from this study, in which the incidence of SBP was higher in the TMP-SMX group (16\%) as compared to the NOR group $(9.4 \%) .^{20}$

In several other studies, the percentage incidence of SBP with NOR prophylaxis ranged from 0 to $35 \% .^{11,16,20,21,24}$ Singh et al, compared TMP-SMX with placebo showed a rate of $3 \%$ in the TMP-SMX group. ${ }^{25}$

The other efficacy parameters, episodes of fever and the rate of extraperitoneal infections (EPI) were comparable in the two groups $(p>0.05)$ of our study.

The incidence of EPI in this study was high, as 5 out 7 (71\%) patients in TMP-SMX group and 10 out of $12(83 \%)$ patients though we failed to find any difference in incidence $(\mathrm{p}>0.99)$.

Lontos et al, showed the rates of EPI were $8 \%$ vs. $16 \%$ (NOR vs. TMP-SMX) group. ${ }^{19}$ A study later conducted by Lontos et al, showed an increased incidence of EPI (15\% vs. $12.5 \%$ in NOR vs. TMP-SMX group). ${ }^{21}$ Alvarez et al, showed the rates of EPI were $31.3 \%$ vs. $24 \%$ (NOR vs. TMP-SMX) group. ${ }^{20}$

In this study the most common EPI observed were UTI, RTI, sepsis and skin infections which was similar to the studies previously conducted by Fernandez et al, Alvarez and Caly et al. ${ }^{9,20,26}$ UTI was the most common EPI among both the groups with $57 \%$ and $60 \%$ of total EPI in TMPSMX and NOR groups, respectively which was comparable to Alvarez et al, $20 \%$ vs. $40 \%$ in TMP-SMX vs. NOR group. ${ }^{20}$

The rates of infections were higher as compared to the previous studies can be due to small sample size, attrition due to drug resistance, can be a compliance issue with the drugs and finally the condition of the patient because most of the patient who got the infection were of old age $(>50$ years) and they might not be able to maintain proper hygiene and health as liver cirrhosis is itself a morbid condition to deal with.

The incidence of death was comparable in both the groups, $14 \%$ vs. $16 \%$ in TMP-SMX vs. NOR, $p>0.99$. These figures were lower as compared to study conducted by Alvarez $20 \%$ vs. $21 \%$ (TMP-SMX vs. NOR). ${ }^{20}$ Lontos showed a mortality rate of about (35\% vs. $43 \%$ in NOR vs. TMP-SMX). ${ }^{19}$ Lontos showed a mortality rate (27.5\% vs. $17.5 \%$ in NOR vs. TMP-SMX). ${ }^{21}$

In this study there were no cases of liver transplantation in both the groups as compared to other previous studies. ${ }^{19,21}$ Huge expenditure might be a reason, our result differs from previous studies.

Our study had few limitations like small sample size, short duration, high attrition and study design did not permit randomization.

\section{CONCLUSION}

These findings in this study suggests that both TMP-SMX and NOR caused same degree of resistance and found to be equally efficacious after a follow up period of 24 weeks prophylactic therapy. TMP-SMX is less expensive compared to NOR, a factor we believe could improve compliance and adherence to treatment. The limited experience with TMP-SMX has been promising and warrants a larger study of longer duration to be more conclusive. In the present study, we conclude that in the absence of any effective prophylactic measures, TMPSMX can be a suitable as well as a cost-effective alternative in the prevention of SBP.

\section{Funding: No funding sources \\ Conflict of interest: None declared}

Ethical approval: The study was approved by the Institutional Ethics Committee, Maulana Azad Medical College, New Delhi, India

\section{REFERENCES}

1. Hoefs JC, Canawati HN, Sapico FL, Hopkins RR, Weiner J, Montgomerie JZ. Spontaneous bacterial peritonitis. Hepatology. 1982;2:399-407.

2. Runyon A. Spontaneous bacterial peritonitis: An explosion of information. Hepatology. 1988;8:171-5. 
3. Runyon BA, McHutchinson JG, Antillon MR. Short course vs. long course antibiotic treatment of spontaneous bacterial peritonitis: A randomized controlled trial of 100 patients. Gastroenterology. 1991;100:1737-42.

4. Tito L, Rimola A, Gines P. Recurrence of spontaneous bacterial peritonitis in cirrhosis: Frequency and predictive factors. Hepatology. 1988;8:27-31.

5. Rimola A, Soto R, Bory F, Arroyo V, Piera C, Rodes J. Reticuloendothelial system phagocytic activity in cirrhosis and its relationship to bacterial infections and prognosis. Hepatology. 1984;4:53-8.

6. Runyon BA. Patients with deficient ascitic fluid opsonic activity are predisposed to spontaneous bacterial peritonitis. Hepatology. 1988;8:632-5.

7. Garcia-Tsao G. Spontaneous bacterial peritonitis. Gastroenterol Clin N Am. 1992;21:257-75.

8. Rimola A. Infections in liver disease. In: McIntyre N, Benhamou JP, Bircher J, Rizzetto M, Rodes J, eds. Oxford Textbook of Clinical Hepatology. Oxford: Oxford University Press; 1991:1272-1284.

9. Fernandez J, Navasa M, Gómez J, Colmenero J, Vila $\mathrm{J}$, Arroyo V, et al. Bacterial infections in cirrhosis: epidemiological changes with invasive procedures and norfloxacin prophylaxis. Hepatology. 2002;35:140-8.

10. Garcia-Tsao G, Albillos A, Barden GE, West AB. Bacterial translocation in acute and chronic portal hypertension. Hepatology. 1993;17:1081-5.

11. Gines P, Rimola A, Planas R. Norfloxacin prevents spontaneous bacterial peritonitis recurrence in cirrhosis: Results of a double-blind, placebocontrolled trial. Hepatology. 1990;12:716-24.

12. Mowat C, Stanley AJ. Review article. Spontaneous bacterial peritonitis- diagnosis, treatment and prevention. Aliment Pharmacol Ther. 2001;15:18519.

13. Dupeyron C, Manganey N, Sedrati L, Campillo B, Fouet P, Leluan G. Rapid emergence of quinolone resistance in cirrhotic patients treated with norfloxacin to prevent spontaneous bacterial peritonitis. Antimicrob Agents Chemother. 1994;38:340-4.

14. Runyon BA. The American Association for the Study of Liver Diseases; Practice guidelines Management of Adult Patients with Ascites Due to Cirrhosis Update 2012: Spontaneous Bacterial peritonitis [Internet]. 2012.

Available at: http://www.aasld.org/sites/default/files/guideline_doc uments/adultascitesenhanced.pdf. Accessed Aug 2 2018

15. European Association for the Study of the Liver; EASL clinical practice guidelines on management of ascites, spontaneous bacterial peritonitis and hepatorenal syndrome in cirrhosis: Spontaneous bacterial peritonitis [Internet]; 2010. Available at: http://www.easl.eu /research/ourcontributions/clinical-practiceguidelines/detail/management-ofascites-spontaneousbacterial-peritonitis-and-hepatorenal- syndrome-incirrhosis/report/4. Accessed Aug 22018.
16. Aparicio JR, Such J, Pascual S, Arroyo A, Plazas J, Girona E, et al. Development of quinolone-resistant strains of Escherichia coli in stools of patients with cirrhosis undergoing norfloxacin prophylaxis: clinical consequences. J Hepatol. 1999 Aug;31(2):277-83.

17. Carratala J, Fernandez-Sevilla A, Tubau F, Dominguez MA, Gudiol F. Emergence of fluoroquinolone-resistant Escherichia coli in fecal flora of cancer patient receiving norfloxacin prophylaxis. Antimicrob Agents Chemother. 1996 Feb;40(2):503-5.

18. Novella M, Sola R, Soriano G, Andreu M, Gana J, Ortiz J, et al. Continuous versus inpatient prophylaxis of the first episode of spontaneous bacterial peritonitis with norfloxacin. Hepatology. 1997;25(3):532-6.

19. Lontos S, Gow PJ, Vaughan RB, Angus PW. Norfloxacin and trimethoprim-sulfamethoxazole have similar efficacy in the prevention of spontaneous bacterial peritonitis. Hepatology. 2008;23:252-5.

20. Alvarez RF, Mattos AA, Correa EB, Cotrim HP, Nascimento TV. Trimethoprim- sulfamethoxazole versus norfloxacin in the prophylaxis of spontaneous bacterial peritonitis in cirrhosis. Arquivos de Gastroenterologia. 2005;42:256-62.

21. Lontos S, Shelton E, Angus P W, Vaughan R, Roberts SK, Gordon A. et al. A randomized controlled study of trimethoprim-sulfamethoxazole versus norfloxacin for the prevention of infection in cirrhotic patients. Journal of Digestive Diseases. 2014;15:260-7.

22. Huovinen P, Mattila T, Kiminki O, Pulkkinen L, Huovinen S, Koskela $\mathrm{M}$, et al. Emergence of Trimethoprim Resistance in Fecal Flora. Antimicrob. Agents Chemother. August 1985; 8(2):354-6.

23. Mavromanolakis E, Maraki S, Samonis G, Tselentis Y, Cranidis A. Effect of norfloxacin, trimethoprimsulfamethoxazole and nitrofurantoin on fecal flora of women with recurrent urinary tract infections. J Chemother. 1997 Jun; 9(3):203-7.

24. Fernández J, Navasa M, Planas R, Montoliu S, Monfort D, Soriano G, et al. Primary prophylaxis of spontaneous bacterial peritonitis delays hepatorenal syndrome and improves survival in cirrhosis. Gastroenterology. 2007;133:818-24.

25. Singh N, Gayowski T, Yu VL, Wagener MM. Trimethoprim-sulfamethoxazole for the prevention of spontaneous bacterial peritonitis in cirrhosis: a randomized trial. Ann Intern Med. 1995;122:595-8.

26. Caly WR, Strauss E. A prospective study of bacterial infections in patients with cirrhosis. J Hepatol. 1993; $18: 353-8$.

Cite this article as: Dutta S, Chawla S, Srivastava S, Loomba P, Roy V. Effect of trimethoprimsulfamethoxazole vs. norfloxacin on fecal $E$. coli resistance pattern and efficacy in patients receiving prophylaxis for spontaneous bacterial peritonitis. Int J Basic Clin Pharmacol 2018;7:2209-15. 